\title{
The Changing Microbial Environment and Chronic Inflammatory Disorders
}

\author{
Graham A.W. Rook, BA, MB, BChir, MD
}

\begin{abstract}
There is much to be gained from examining human diseases within the expanding framework of Darwinian medicine. This is particularly true of those conditions that change in frequency as populations develop from the human "environment of evolutionary adaptedness" to the living conditions of the rich industrialized countries. This development entails major changes in lifestyle, leading to reductions in contact with environmental microorganisms and helminths that have evolved a physiologic role as drivers of immunoregulatory circuits. It is suggested that a deficit in immunoregulation in rich countries is contributing not only to increases in the incidence of allergic disorders but also to increases in other chronic inflammatory conditions that are exacerbated by a failure to terminate inappropriate inflammatory reponses. These include autoimmunity, neuroinflammatory disorders, atherosclerosis, depression associated with raised inflammatory cytokines, and some cancers.
\end{abstract}

T 1989, Strachan showed that in young adults, a history 1 of hay fever was inversely related to the number of children in the family when the subject was 11-years old. ${ }^{1}$ Further studies suggested that having many siblings, especially older ones, correlated with diminished risk of hay fever, and these findings were considered consistent with a protective influence of postnatal infection, which might be lost in the presence of modern hygiene. ${ }^{2}$ So the "hygiene hypothesis" was born. The concept was initially vague and lacked mechanistic explanations, so in the 28 years since the original study, a multitude of different, often mutually exclusive, versions of this hypothesis have been considered. Often this has led to the "disproving" of hypotheses that few had intended to propose in the first place. However, during the last 9 years, an essentially new hypothesis has emerged, which we have preferred to designate "the old friends hypothesis." This hypothesis might not be relevant to Strachan's original findings, which remain unexplained, but it does have very broad importance for understanding the influence of changing patterns of microbial exposure on trends in human disease and is leading to encouraging clinical trials. Moreover, the old friends hypothesis belongs within the rapidly growing

Graham A.W. Rook: Centre for Infectious Diseases and International Health, Windeyer Institute of Medical Sciences, University College London, London, UK.

Correspondence to: Graham A.W. Rook, BA, MB, BChir, MD, 46 Cleveland Street, London, UK W1T 4JF; e-mail: g.rook@ucl.ac.uk.

DOI $10.2310 / 7480.2008 .00013$ framework of "evolutionary medicine," which seeks to clarify our understanding of disease by considering our evolutionary history.

This review first outlines various "failed" versions of the hygiene hypothesis and then describes the old friends hypothesis and its implications not only for allergic disorders but also for other chronic inflammatory disorders, such as autoimmunity and inflammatory bowel disease (IBD). Finally, evidence is tentatively outlined suggesting that the concept might be relevant to other disorders in which proinflammatory cytokines play a major role, such as the metabolic syndrome, atherosclerosis, depression, and some types of neurodegeneration.

\section{Failed Hypotheses}

\section{Childhood Infections}

Strachan's studies pointed to the possibility that the common infections of childhood might protect children from allergic disorders. Many allergologists found this view difficult to accept because allergies are rife in the inner cities of rich countries, where these infections are particularly common. More importantly, excellent studies have indicated that these infections do not protect children from allergies. ${ }^{3}$ Most strikingly, children in daycare centres do not have an increased risk of atopy if they wash more often and reduce their infection rate. Thus, prevention of common respiratory tract and enteric infections during early childhood does not change later allergic morbidity. ${ }^{4}$ It now seems likely that Strachan's original findings were 
due to the decreasing incidence of hepatitis A virus (HAV) infection during the period in which the sibings studied were born. ${ }^{1}$ HAV binds to lymphocytes via a receptor that modulates the development of T-cell subsets. ${ }^{5}$ Thus, it is part of the hygiene hypothesis but rather separate from the main theme of this review.

\section{Domestic Hygiene}

A second, partially overlapping view, largely created by journalists attracted to the word hygiene, was that home hygiene itself was to blame. Newspaper articles implied that we should avoid hygienic practices such as the use of bactericidal products, and interviewers tried to make scientists advise listeners to let their children live in squalor. Again, a detailed recent report rejected this simplistic concept. ${ }^{6}$ The history of the major changes in hygiene practices shows that they did not occur at the right times to correlate with increases in the incidence of allergies. ${ }^{6}$

\section{T Helper 1/T Helper 2 Balance or Effector/Regulator Balance?}

Although these hypotheses were failing, the suggested mechanism was overproduction of T helper 2 (Th)2 cells as a consequence of diminished infections and consequent diminished production of Th1 cells. According to this interpretation, the critical issue was Th1/Th2 balance, but this was never a strong hypothesis. First, Th1 cytokines such as interferon- $\gamma$ (IFN- $\gamma$ ) are present in large quanitites in both asthma ${ }^{7}$ and established atopic dermatitis. ${ }^{8}$ Second, profound defects in the interleukin (IL)-12 or IFN- $\gamma$ (Th1) pathways do not lead to an increased incidence or severity of allergic disorders, implying that in humans Th1 is not a physiologic regulator of Th2 responses. ${ }^{9}$ Finally, the Th1/Th2 balance hypothesis has been untenable since as early as $1998,{ }^{10}$ by which time, it had been well documented that there was a simultaneous increase in Th1-mediated chronic inflammatory diseases (type 1 diabetes, multiple sclerosis, inflammatory bowel disease), ${ }^{11}$ occurring in the same countries as the increases in allergic disorders. ${ }^{12}$ Moreover, individuals infected by helminths, which enhance Th2 responses, are paradoxically less likely to have allergic sensitization or allergic disorders, and treating the infection leads to increased allergic sensitization. ${ }^{13}$

These points all suggested that the critical problem was not Th1/Th2 balance but rather a broad and increasing failure in the rich developed countries of immunoregula- tory mechanisms that should terminate inappropriate inflammatory responses, whether Th1 or Th2 and whether targeting allergens or self (autoimmunity) or gut contents (IBD). This is now the prevailing view.

\section{Balance of Effector to Regulatory T Cells}

In support of this concept, immunoregulation has been shown to be faulty in individuals suffering from allergic disorders $^{14}$ and some autoimmune diseases, ${ }^{15,16}$ and probably in IBD too. ${ }^{17,18}$ A striking example in autoimmunity is a recent experiment of nature. ${ }^{19}$ Patients in Argentina suffering from multiple sclerosis were followed up for 4.6 years. It was found that those who developed parasite infections (which were not treated) had significantly fewer exacerbations than those who did not. Moreover, they also developed regulatory $\mathrm{T}$ cells (Tregs) $\left(\mathrm{CD} 4^{+}, \mathrm{CD} 25 \mathrm{hi}\right.$, Foxp $\left.3^{+}\right)$, which specifically responded to myelin basic protein. In other words, the presence of the parasite appeared to drive the development of Tregs that recognized the autoantigen and inhibited the disease process.

It is clear that a failure of immunoregulatory mechanisms can indeed lead to simultaneous increases in diverse types of pathology because genetic defects of Foxp3, a transcription factor that plays a crucial role in the development and function of Tregs, leads to a syndrome known as X-linked autoimmunity-allergic dysregulation syndrome (XLAAD), which includes aspects of allergy, autoimmunity, and enteropathy. ${ }^{20}$

\section{Old Friends Hypothesis}

Rather than focusing on the common infections of childhood, the old friends hypothesis draws on epidemiologic studies demonstrating that protection from allergies is associated with living in developing countries and with the farming environment. ${ }^{21,22}$ These observations have been repeated many times in different environments and appear solid. Humans evolved in a hunter-gatherer environment, which is regarded as our environment of evolutionary adaptedness. ${ }^{23}$ Much subsequent human evolution has been cultural rather than genetic. Nevertheless, the development of farming about 10,000 years ago led to a dramatic change in humans' microbial environment and to a further series of genetic adaptations. The intervening $\approx 500$ generations are sufficient to have allowed major changes in gene frequencies. For example, farmers needed to be able to digest the lactose in milk from domesticated animals, and the frequency of relevant 
mutations in the gene encoding lactase has reached more than $90 \%$ in many populations. ${ }^{24}$

Against this background, the old friends hypothesis suggests that the lack of appropriate levels of immunoregulatory pathways in rich northern countries is a consequence of diminished exposure to two categories of organism. First, harmless organisms associated with mud, untreated water, and fermenting vegetable matter were present throughout mammalian evolution but are greatly diminished in a world of concrete, treated water, and washed vegetables. These organisms include various Lactobacillus strains, saprophytic mycobacteria, other actinomycetes, and, no doubt, many other genera. Second, helminthic infections, always present in humans' progenitors but possibly increased in variety and load when animal husbandry began, are still common in developing countries but almost completely absent from rich ones. ${ }^{25}$ The former needed to be tolerated because they were harmless but always present in large numbers in food and water. The helminthic parasites needed to be tolerated because, although not always harmless, once they were established in the host, any effort by the immune system to eliminate them was likely to cause tissue damage. For instance, a futile effort to destroy Brugia malayi microfilariae resulted in lymphatic blockage and elephantiasis. ${ }^{26}$

A cartoon of the pathway by which these organisms are currently thought to prime immunoregulation and mediate protection from allergies, autoimmunity, and IBD is shown in Figure 1. The host-parasite relationship evolved so that rather than provoking needless, damaging, aggressive immune responses, these organisms cause a pattern of maturation of dendritic cells (DCs) such that these drive Tregs rather than Th1 or Th2 effector cells. $^{27,28}$ This, in turn, leads to two mechanisms that help control inappropriate inflammation. First, the constitutive presence of the old friends causes continuous background activation of the dendritic regulatory cells (DCregs) and of Tregs specific for the old friends themselves, resulting in constant background bystander suppression of inflammatory responses. Second, these DCregs inevitably sample self and gut contents and allergens and so induce Tregs specific for the illicit target antigens of the three groups of chronic inflammatory disorder. These inhibitory mechanisms are aborted when there are legitimate "danger" signals. ${ }^{29}$

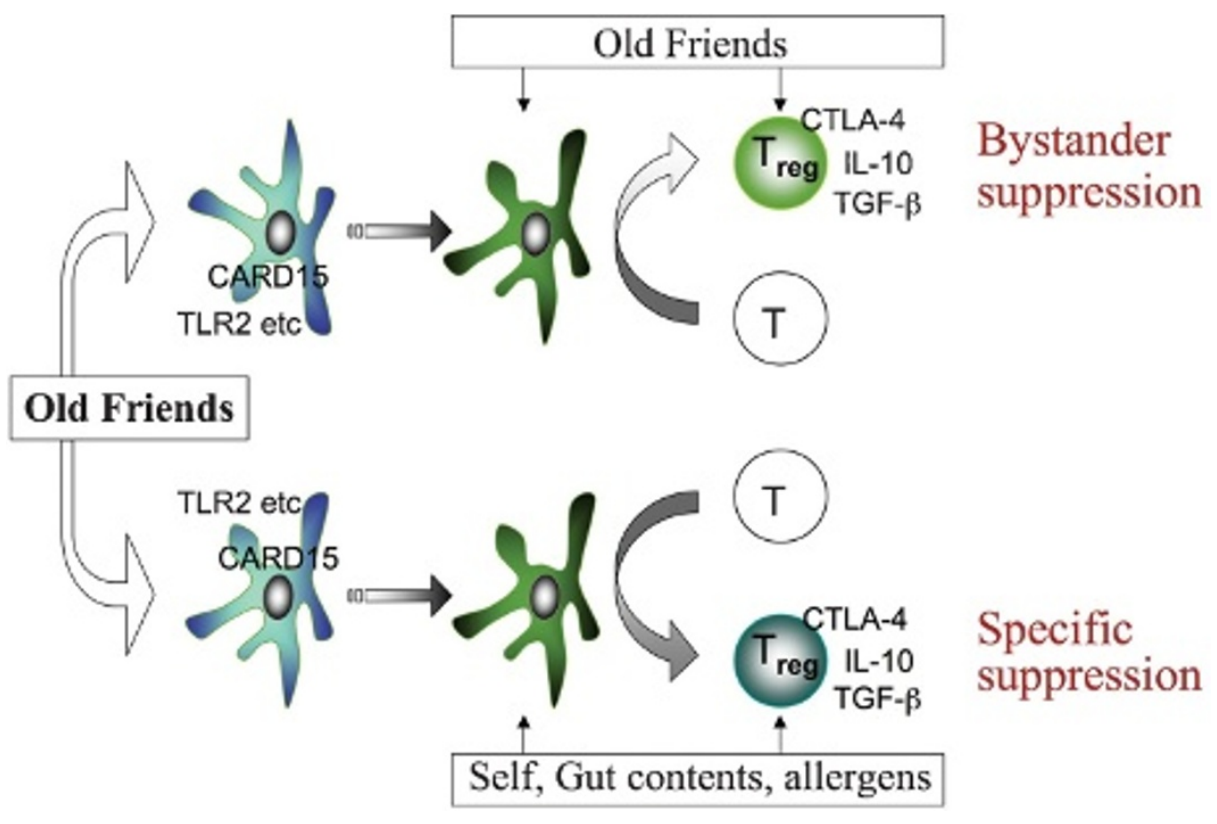

Figure 1. Organisms such as helminths and environmental saprophytes, which are part of mammalian evolutionary history ("old friends") and must be tolerated, are detected by pattern recognition receptors such as Toll-like receptor 2 (TLR2) and CARD15 (caspase recruitment domain family, member 15) on dendritic cells (DCs). The DCs mature into regulatory DCs that drive regulatory T cell (Treg) responses to the antigens of these organisms. The continuing presence of these antigens in the gut flora, in food, or resident as parasites such as microfilariae leads to continuous background release of regulatory cytokines from these Tregs, exerting bystander suppression of other responses, as shown in the upper arm of the figure. Meanwhile, the increased numbers of regulatory DCs lead to increased processing by such DCs of self-antigens, gut content antigens, and allergens, as shown in the lower arm of the figure. Therefore, the numbers of Tregs specifically triggered by these antigens is also increased, downregulating autoimmunity, inflammatory bowel disease, and allergies, respectively. CTLA-4 = cytotoxic T-lymphocyte antigen 4 ; IL-10 = interleukin-10; TGF- $\beta=$ transforming growth factor $\beta$. 
The validity of this hypothetical model is supported by clinical trials and experimental models in which exposure to microorganisms that were ubiquitous during mammalian evolutionary history but are currently "missing" from the environment in rich countries (or from animal units with specific pathogen-free facilities) will treat allergy, ${ }^{30-32}$ autoimmunity, ${ }^{33}$ or intestinal inflammation. ${ }^{34}$

We do not understand all of the ways in which DCregs and Tregs evoked by the old friends block or terminate inflammatory responses. However, we know that the release of the anti-inflammatory cytokines IL-10 and transforming growth factor (TGF) $\beta$ is often involved. ${ }^{30,31}$ The next sections summarize the evidence that a relative lack of Tregs and DCregs, leading secondarily to a decrease in immunoregulation and a decrease in these anti-inflammatory mediators, might be contributing to the increases in a wide variety of disorders in the developed countries (Figure 2).

\section{IL-10-Dependent Disorders}

In addition to the allergic disorders, autoimmunity, and IBD, all of which have been considered in detail in relation to the old friends hypothesis in the past, ${ }^{11,25}$ several other disorders are also increasing and are likely to be exacerbated or made more common by a switch in the balance of inflammatory to anti-inflammatory mechanisms (see Figure 2).

\section{Atherosclerosis}

The metabolic syndrome, which involves abdominal obesity, hypertriglyceridemia, low high-density lipoprotein cholesterol, and insulin resistance, has risen to a prevalence of $41 \%$ in New York. ${ }^{35}$ It has been observed recently that whereas women with uncomplicated obesity have increased serum levels of IL-10, those with the metabolic syndrome do not. ${ }^{36}$ Could this imply less regulatory cell activity? The hypothesis is strengthened by considering atherosclerosis, which is a $\mathrm{T}$ cell-mediated inflammatory lesion in blood vessel walls and is considerably more common in patients with the metabolic syndrome.

Atherosclerotic plaques are inflammatory lesions driven mostly by Th1 cells. ${ }^{37}$ Several independent groups have found that IL-10 and TGF- $\beta$ have a downregulatory

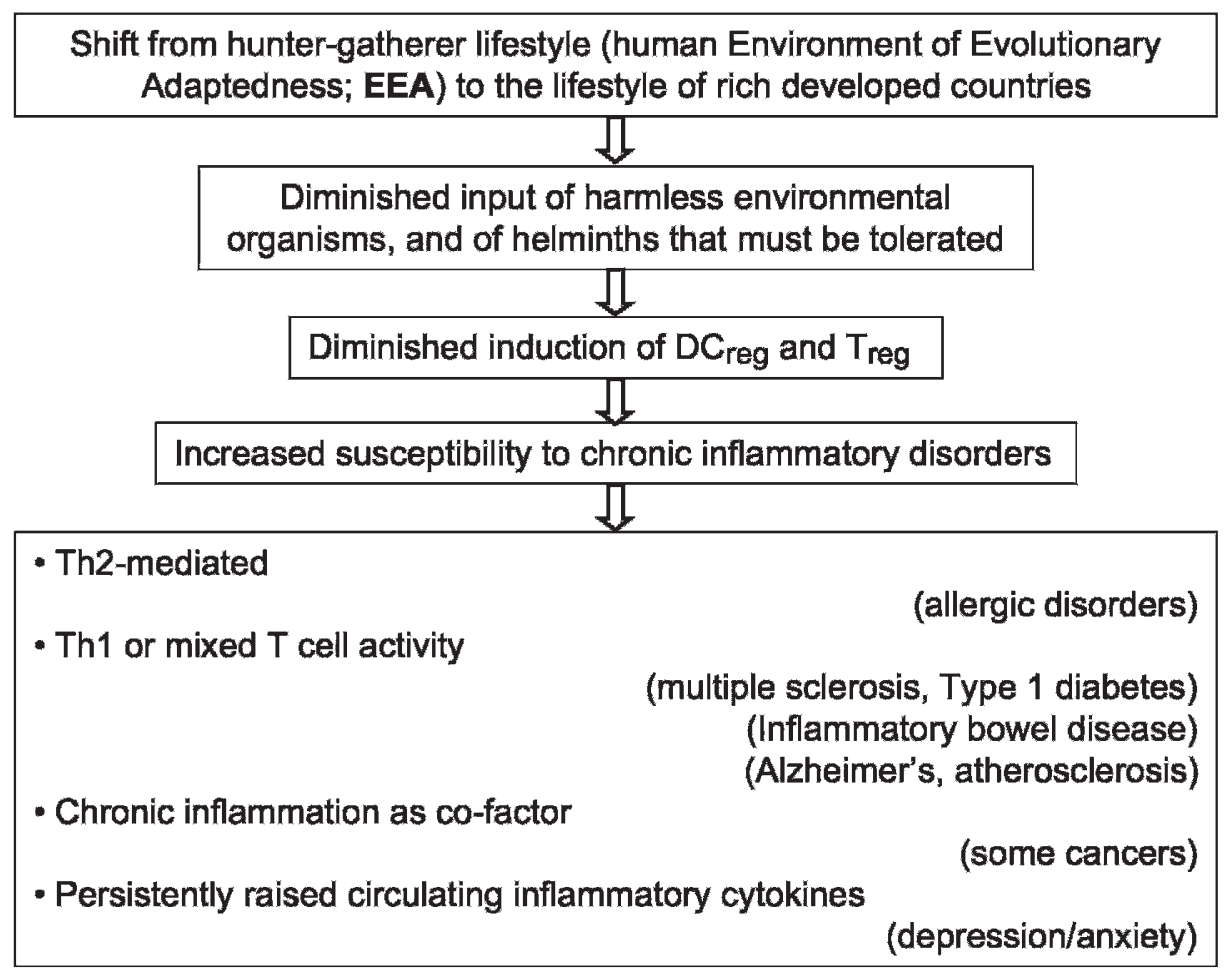

Figure 2. Human physiology was shaped by the hunter-gatherer way of life, which is regarded as the human "environment of evolutionary adaptedness," although there have been further adaptations during the approximately 10,000 years ( $\approx 500$ generations) since the introduction of farming and livestock. Most human evolution has been cultural and technological rather than genetic, and a gene-environment misfit may be occurring. Harmless organisms that were abundant in food and water (such as environmental actinomycetes) and helminths that had to be tolerated developed a role in the induction of immunoregulatory circuits. Without these, there may be a failure to terminate inappropriate inflammatory responses, leading to an increased susceptibility to chronic inflammatory disorders, the precise nature of which depends on the genetics and history of the individual. DCreg $=$ dendritic regulatory cells; $\mathrm{Th}=\mathrm{T}$ helper; Treg $=$ regulatory $\mathrm{T}$ cells. 
effect on the development of atherosclerotic plaques. ${ }^{37}$ Atherosclerosis is exaggerated in IL-10-deficient mice. ${ }^{38}$ By contrast, mice with transgenic T cells overexpressing IL-10 are protected from atherosclerosis, ${ }^{39}$ and in several experimental models, transfer of Tregs will also inhibit atherosclerosis. ${ }^{40}$ Infection with Schistosoma mansoni inhibits atherogenesis in mice, and although the authors attributed this to effects on lipid metabolism, induction of Tregs is likely. ${ }^{41}$ Further evidence was reviewed by Kuiper and colleagues. ${ }^{42}$

There is similar evidence that IL-10 has a beneficial role in human atherosclerotic plaques, ${ }^{37,43-45}$ and serum levels of IL-10 are reduced in patients with unstable angina. ${ }^{46}$ Interestingly, atherosclerotic lesions contain a very low percentage of Tregs as determined by direct immunohistochemistry. ${ }^{47}$

\section{Alzheimer Disease}

The neurodegenerative disorders Alzheimer disease (AD) and Parkinson disease (PD) both appear to be mediated by inflammation. ${ }^{48}$ This is apparent from both the pathol$\mathrm{ogy}^{48}$ and the epidemiology. Japanese American men in Honolulu were examined 25 years after a blood sample was taken to measure $\mathrm{C}$-reactive protein (CRP), using very sensitive assays. ${ }^{49}$ Raised CRP was associated with a higher incidence of $\mathrm{AD}$ and vascular dementia 25 years later. As mentioned earlier, the metabolic syndrome is itself associated with inflammatory cytokines, and a study in the United States yielded support for the hypothesis that the metabolic syndrome contributes to eventual cognitive impairment in the elderly, particularly in those with a high serum CRP and IL-6. ${ }^{50}$ Other studies have yielded preliminary evidence that $\mathrm{AD}$ is associated with single nucleotide polymorphisms (SNPs) that lead to increased production of IL- $6^{51}$ or tumor necrosis factor (TNF). ${ }^{52}$ Moreover, a large meta-analysis concluded that prolonged intake of nonsteroidal anti-inflammatory drugs can give some protection against $\mathrm{AD} .^{53,54}$

There is also some evidence that the neurodegenerative conditions are more common in individuals with SNPs of their IL-10 genes that modulate production of this cytokine. For instance, in an Italian population, the presence of the $-1082 \mathrm{~A}$ allele was proposed as a genetic risk factor for $\mathrm{AD}^{55}$ Other studies found similar associations, although not always with the same allele or haplotype ${ }^{51,56,57}$ and a study based in Germany found no associations at all, ${ }^{58}$ so the matter remains unresolved. ${ }^{54}$ The role of IL-10 is equally unclear in relation to PD. IL-10 SNPs were not related to sporadic PD in a Polish population, ${ }^{59}$ but a Swedish study that documented the $-1082 \mathrm{~A} / \mathrm{G}$ SNP found that the age at onset of PD was delayed by 5 years in individuals with two $G$ alleles compared with individuals with two A alleles. ${ }^{60}$ Meanwhile, there is accumulating evidence that TGF- $\beta$ might have anti-AD effects both because of its immunoregulatory and anti-inflammatory properties and because it enhances clearance of amyloid- $\beta .^{54}$

\section{Depression and Anxiety}

Some stress-related psychiatric conditions, particularly depression and anxiety, are associated with markers of ongoing inflammation, even in the absence of any accompanying inflammatory disorder. ${ }^{61}$ Thus, depressed subjects may have raised proinflammatory cytokines and evidence of an ongoing acute-phase response. Moreover, proinflammatory cytokines can induce depression, which is commonly seen in patients with cancer or hepatitis when they are treated with IL-2 or IFN- $\gamma$. In these patients, brain imaging shows a pattern similar to that which accompanies spontaneously occurring depression, and the depression can be treated with paroxetine, a serotonin reuptake inhibitor antidepressant. ${ }^{62}$ Similarly, there is evidence that depression can be associated with polymorphisms that lead to the overproduction of proinflammatory cytokines, ${ }^{63}$ whereas in sharp contrast, treatments that neutralize these cytokines can alleviate depression. ${ }^{64}$ Therefore, some psychiatric disorders in developed countries might be attributable to failure of immunoregulatory circuits to terminate ongoing inflammatory responses, leading to prolonged "sickness behaviour" and mood changes. This view is further supported by the fact that depression is associated with low expression of TGF- $\beta$ and IL-10 relative to expression of proinflammatory cytokines. ${ }^{65,66}$ Moreover, antidepressants increase secretion of IL-10. ${ }^{67}$

Recently, unexpected improvements in mood were observed during clinical trials with an immunomodulatory vaccine that induces Tregs. This led to an investigation of this material in a mouse model and to the discovery that it activates a specific group of brain serotoninergic neurons involved in the pathophysiology of mood disorders and exerts a fluoxetine hydrochloride (Prozac)-like effect in an industry standard test for antidepressant activity. ${ }^{68}$ This area has now been reviewed in depth. ${ }^{69}$

\section{Cancer}

Chronic inflammatory lesions, such as those induced by chronic infections (viruses, Chlamydia, or bacteria), 
asbestos, or chronic exposure to smoke or alcohol, are all associated with increased cancer risk. ${ }^{70}$ This is partly because inflammatory mediators are involved in control of cell replication, angiogenesis, and cell migration and also drive increased levels of reactive oxygen intermediates that can cause deoxyribonucleic acid (DNA) damage. ${ }^{70}$ Many of these functions of inflammation are regulated by the transcription factor nuclear factor $\kappa(\mathrm{NF}-\kappa \mathrm{B})$, and manipulating the activity of NF- $\kappa B$ has profound effects on tumorigenesis. ${ }^{71}$ Interestingly, TNF- $\alpha^{-1-}$ or TNF receptor $1^{-1-}$ mice are more resistant to chemically induced carcinogenesis. ${ }^{70,72}$ Similarly, several SNPs of chemokines and cytokines are associated with malignancy. ${ }^{70}$ Conversely, anti-inflammatory drugs may be protective. Regular input of nonsteroidal anti-inflammatory drugs, such as aspirin, that inhibit cyclooxygenase-2 (the inducible form of prostaglandin $\mathrm{H}$ synthase) is associated with reduced risk of colorectal cancer. ${ }^{73}$ Esophageal cancer provides a vivid example of the role of inflammation; reflux of gastric acid, alcohol, and tobacco all predispose individuals to esophageal cancer. ${ }^{74}$

Clearly, this is a complex issue where cancer is concerned. It is reasonable to suggest that failing immunoregulation might allow chronic inflammation and so predispose individuals to carcinogenesis. On the other hand, excessively effective immunoregulation might impede the immune system's attempts to destroy cancer cells once the cancer is established. ${ }^{75}$ Nevertheless, a proinflammatory haplotype of SNPs in IL-6, IL-10, and TNF- $\alpha$ is associated with a poor prognosis in gastroesophageal malignancy, ${ }^{76}$ and it is clear that the inflammatory response can provide mediators that assist the growth and spread of the cancer. ${ }^{70}$ Thus, diminished background immunoregulation in rich countries, as explained by the old friends hypothesis, might explain some of the increase in certain cancers.

\section{Conclusions}

The original hygiene hypothesis gave rise to several daughter hypotheses, all of which lacked epidemiologic and historical credibility, as outlined above. This review attempts to show how a broader view, focusing on major changes in lifestyle that accompany the shift from hunter-gatherer to industrialized society, passing via herding and farming, can lead to a hypothesis that falls within Darwinian medicine and has considerable explanatory power. It is clear that multiple environmental changes must contribute to changing patterns of disease, and this brief overview does not intend to imply that diminished input of Treg-inducing organisms such as helminths and harmless environmental saprophytes is the only factor. There are numerous other ways in which harmless microorganisms or infections can influence health. For example, changes in bowel flora secondary to dietary changes will play a role, and obesity itself increases inflammatory cytokine levels. Similarly, urbanization led to increased incidences of diseases such as tuberculosis, and selection of genetic variants confering resistance to such infections might lead to increased susceptibility to autoimmunity. This review therefore covers only one subset of the relevant mechanisms and emphasizes our increasing awareness of humans' place within the evolutionary framework of the biosphere. This must be considered in the light of humans' unique ability to change their environment by means of technology, with little accompanying adaptive genetic change. Therefore, it is logical to explore the possibility of a gene-environment misfit, leading to increased susceptibility to chronic inflammatory disorders. The list of disorders discussed here in this context is illustrative, and many others might need to be added.

\section{References}

1. Strachan DP. Hay fever, hygiene, and household size. Br Med J 1989;299:1259-60.

2. Strachan DP, Taylor EM, Carpenter RG. Family structure, neonatal infection, and hay fever in adolescence. Arch Dis Child 1996;74: 422-6.

3. Benn CS, Melbye M, Wohlfahrt J, et al. Cohort study of sibling effect, infectious diseases, and risk of atopic dermatitis during first 18 months of life. BMJ 2004;328:1223.

4. Dunder T, Tapiainen T, Pokka T, Uhari M. Infections in child day care centers and later development of asthma, allergic rhinitis, and atopic dermatitis: prospective follow-up survey 12 years after controlled randomized hygiene intervention. Arch Pediatr Adolesc Med 2007;161:972-7.

5. Umetsu DT, McIntire JJ, DeKruyff RH. TIM-1, hepatitis A virus and the hygiene theory of atopy: association of TIM-1 with atopy. J Pediatr Gastroenterol Nutr 2005;40 Suppl 1:S43.

6. Stanwell-Smith R, Bloomfield $\mathrm{S}$. The hygiene hypothesis and its implications for home hygiene. Milan: NextHealth Srl; 2004.

7. Krug N, Madden J, Redington AE, et al. T-cell cytokine profile evaluated at the single cell level in BAL and blood in allergic asthma. Am J Respir Cell Mol Biol 1996;14:319-26.

8. Klunker S, Trautmann A, Akdis M, et al. A second step of chemotaxis after transendothelial migration: keratinocytes undergoing apoptosis release IFN-gamma-inducible protein 10, monokine induced by IFN-gamma, and IFN-gamma-inducible alphachemoattractant for $\mathrm{T}$ cell chemotaxis toward epidermis in atopic dermatitis. J Immunol 2003;171:1078-84.

9. Lammas DA, Casanova JL, Kumararatne DS. Clinical consequences of defects in the IL-12-dependent interferon-gamma (IFN-gamma) pathway. Clin Exp Immunol 2000;121:417-25.

10. Rook GAW, Stanford JL. Give us this day our daily germs. Immunol Today 1998;19:113-6. 
11. Bach JF. The effect of infections on susceptibility to autoimmune and allergic diseases. N Engl J Med 2002;347:911-20.

12. Stene LC, Nafstad P. Relation between occurrence of type 1 diabetes and asthma. Lancet 2001;357:607.

13. Yazdanbakhsh M, Kremsner PG, van Ree R. Allergy, parasites, and the hygiene hypothesis. Science 2002;296:490-4.

14. Akdis M, Verhagen J, Taylor A, et al. Immune responses in healthy and allergic individuals are characterized by a fine balance between allergen-specific T regulatory 1 and T helper 2 cells. J Exp Med 2004;199:1567-75.

15. Viglietta V, Baecher-Allan C, Weiner HL, Hafler DA. Loss of functional suppression by $\mathrm{CD} 4+\mathrm{CD} 25+$ regulatory $\mathrm{T}$ cells in patients with multiple sclerosis. J Exp Med 2004;199:971-9.

16. Kriegel MA, Lohmann T, Gabler C, et al. Defective suppressor function of human CD4+ CD25+ regulatory $\mathrm{T}$ cells in autoimmune polyglandular syndrome type II. J Exp Med 2004;199: 1285-91.

17. Kraus TA, Toy L, Chan L, et al. Failure to induce oral tolerance to a soluble protein in patients with inflammatory bowel disease. Gastroenterology 2004;126:1771-8.

18. Powrie F, Read S, Mottet C, et al. Control of immune pathology by regulatory T cells. Novartis Found Symp 2003;252:92-8.

19. Correale J, Farez M. Association between parasite infection and immune responses in multiple sclerosis. Ann Neurol 2007;61:97108.

20. Wildin RS, Smyk-Pearson S, Filipovich AH. Clinical and molecular features of the immunodysregulation, polyendocrinopathy, enteropathy, X linked (IPEX) syndrome. J Med Genet 2002;39:537-45.

21. Strachan D, Sibbald B, Weiland S, et al. Worldwide variations in prevalence of symptoms of allergic rhinoconjunctivitis in children: the International Study of Asthma and Allergies in Childhood (ISAAC). Pediatr Allergy Immunol 1997;8:161-76.

22. Riedler J, Braun-Fahrlander C, Eder W, et al. Exposure to farming in early life and development of asthma and allergy: a crosssectional survey. Lancet 2001;358:1129-33.

23. Foley R. The adaptive legacy of human evolution: a search for the environment of evolutionary adaptedness. Evol Anthropol 1995;4: 194-203.

24. Tishkoff SA, Reed FA, Ranciaro A, et al. Convergent adaptation of human lactase persistence in Africa and Europe. Nat Genet 2007; 39:31-40.

25. Rook GA, Adams V, Hunt J, et al. Mycobacteria and other environmental organisms as immunomodulators for immunoregulatory disorders. Springer Semin Immunopathol 2004;25:23755.

26. Babu S, Blauvelt CP, Kumaraswami V, Nutman TB. Regulatory networks induced by live parasites impair both Th1 and Th2 pathways in patent lymphatic filariasis: implications for parasite persistence. J Immunol 2006;176:3248-56.

27. van der Kleij D, Latz E, Brouwers JF, et al. A novel host-parasite lipid cross-talk. Schistosomal lyso-phosphatidylserine activates Toll-like receptor 2 and affects immune polarization. J Biol Chem 2002;277:48122-9.

28. Smits HH, Engering A, van der Kleij D, et al. Selective probiotic bacteria induce IL-10-producing regulatory $\mathrm{T}$ cells in vitro by modulating dendritic cell function through dendritic cell-specific intercellular adhesion molecule 3-grabbing nonintegrin. J Allergy Clin Immunol 2005;115:1260-7.
29. Pasare C, Medzhitov R. Toll pathway-dependent blockade of CD4+CD25+ $\mathrm{T}$ cell-mediated suppression by dendritic cells. Science 2003;299:1033-6.

30. Zuany-Amorim C, Sawicka E, Manlius C, et al. Suppression of airway eosinophilia by killed Mycobacterium vaccae-induced allergen-specific regulatory T-cells. Nat Med 2002;8:625-9.

31. Wilson MS, Taylor MD, Balic A, et al. Suppression of allergic airway inflammation by helminth-induced regulatory T cells. J Exp Med 2005;202:1199-212.

32. Ricklin-Gutzwiller ME, Reist M, Peel JE, et al. Intradermal injection of heat-killed Mycobacterium vaccae in dogs with atopic dermatitis: a multicentre pilot study. Vet Dermatol 2007;18:87-93.

33. Zaccone P, Fehervari Z, Jones FM, et al. Schistosoma mansoni antigens modulate the activity of the innate immune response and prevent onset of type 1 diabetes. Eur J Immunol 2003;33:1439-49.

34. Summers RW, Elliott DE, Urban JF Jr, et al. Trichuris suis therapy in Crohn's disease. Gut 2005;54:87-90.

35. Rundek $\mathrm{T}$, White $\mathrm{H}$, Boden-Albala $\mathrm{B}$, et al. The metabolic syndrome and subclinical carotid atherosclerosis: the Northern Manhattan Study. J Cardiometab Syndr 2007;2:24-9.

36. Esposito K, Pontillo A, Giugliano F, et al. Association of low interleukin-10 levels with the metabolic syndrome in obese women. J Clin Endocrinol Metab 2003;88:1055-8.

37. Mallat Z, Ait-Oufella H, Tedgui A. Regulatory T-cell immunity in atherosclerosis. Trends Cardiovasc Med 2007;17:113-8.

38. Mallat Z, Besnard S, Duriez M, et al. Protective role of interleukin10 in atherosclerosis. Circ Res 1999;85:e17-24.

39. Pinderski LJ, Fischbein MP, Subbanagounder G, et al. Overexpression of interleukin-10 by activated $\mathrm{T}$ lymphocytes inhibits atherosclerosis in LDL receptor-deficient mice by altering lymphocyte and macrophage phenotypes. Circ Res 2002;90:106471.

40. Ait-Oufella H, Salomon BL, Potteaux S, et al. Natural regulatory T cells control the development of atherosclerosis in mice. Nat Med 2006;12:178-80.

41. Doenhoff MJ, Stanley RG, Griffiths K, Jackson CL. An antiatherogenic effect of Schistosoma mansoni infections in mice associated with a parasite-induced lowering of blood total cholesterol. Parasitology 2002;125:415-21.

42. Kuiper J, van Puijvelde GH, van Wanrooij EJ, et al. Immunomodulation of the inflammatory response in atherosclerosis. Curr Opin Lipidol 2007;18:521-6.

43. Uyemura K, Demer LL, Castle SC, et al. Cross-regulatory roles of interleukin (IL)-12 and IL-10 in atherosclerosis. J Clin Invest 1996; 97:2130-8.

44. Mallat Z, Heymes C, Ohan J, et al. Expression of interleukin-10 in advanced human atherosclerotic plaques: relation to inducible nitric oxide synthase expression and cell death. Arterioscler Thromb Vasc Biol 1999;19:611-6.

45. Pinderski Oslund LJ, Hedrick CC, Olvera T, et al. Interleukin-10 blocks atherosclerotic events in vitro and in vivo. Arterioscler Thromb Vasc Biol 1999;19:2847-53.

46. Smith DA, Irving SD, Sheldon J, et al. Serum levels of the antiinflammatory cytokine interleukin-10 are decreased in patients with unstable angina. Circulation 2001;104:746-9.

47. de Boer OJ, van der Meer JJ, Teeling P, et al. Low numbers of FOXP3 positive regulatory $\mathrm{T}$ cells are present in all developmental stages of human atherosclerotic lesions. PLoS ONE 2007;2:e779. 
48. Rogers J, Mastroeni D, Leonard B, et al. Neuroinflammation in Alzheimer's disease and Parkinson's disease: are microglia pathogenic in either disorder? Int Rev Neurobiol 2007;82:235-46.

49. Schmidt R, Schmidt H, Curb JD, et al. Early inflammation and dementia: a 25-year follow-up of the Honolulu-Asia Aging Study. Ann Neurol 2002;52:168-74.

50. Yaffe K, Kanaya A, Lindquist K, et al. The metabolic syndrome, inflammation, and risk of cognitive decline. JAMA 2004;292:2237-42.

51. Arosio B, Trabattoni D, Galimberti L, et al. Interleukin-10 and interleukin-6 gene polymorphisms as risk factors for Alzheimer's disease. Neurobiol Aging 2004;25:1009-15.

52. Ramos EM, Lin MT, Larson EB, et al. Tumor necrosis factor alpha and interleukin 10 promoter region polymorphisms and risk of late-onset Alzheimer disease. Arch Neurol 2006;63:1165-9.

53. Etminan M, Gill S, Samii A. Effect of non-steroidal anti-inflammatory drugs on risk of Alzheimer's disease: systematic review and meta-analysis of observational studies. BMJ 2003;327:128.

54. Wyss-Coray T. Inflammation in Alzheimer disease: driving force, bystander or beneficial response? Nat Med 2006;12:1005-15.

55. Lio D, Licastro F, Scola L, et al. Interleukin-10 promoter polymorphism in sporadic Alzheimer's disease. Genes Immun 2003;4:234-8.

56. Bagnoli S, Cellini E, Tedde A, et al. Association of IL10 promoter polymorphism in Italian Alzheimer's disease. Neurosci Lett 2007; 418:262-5.

57. Ma SL, Tang NL, Lam LC, Chiu HF. The association between promoter polymorphism of the interleukin-10 gene and Alzheimer's disease. Neurobiol Aging 2005;26:1005-10.

58. Depboylu C, Du Y, Muller U, et al. Lack of association of interleukin-10 promoter region polymorphisms with Alzheimer's disease. Neurosci Lett 2003;342:132-4.

59. Bialecka M, Klodowska-Duda G, Kurzawski M, et al. Interleukin10 gene polymorphism in Parkinson's disease patients. Arch Med Res 2007;38:858-63.

60. Hakansson A, Westberg L, Nilsson S, et al. Investigation of genes coding for inflammatory components in Parkinson's disease. Mov Disord 2005;20:569-73.

61. Raison CL, Capuron L, Miller AH. Cytokines sing the blues: inflammation and the pathogenesis of depression. Trends Immunol 2006;27:24-31.

62. Musselman DL, Lawson DH, Gumnick JF, et al. Paroxetine for the prevention of depression induced by high-dose interferon alfa. $\mathrm{N}$ Engl J Med 2001;344:961-6.
63. Wilson AG, Gordon C, di Giovine FS, et al. A genetic association between systemic lupus erythematosus and tumor necrosis factor alpha. Eur J Immunol 1994;24:191-5.

64. Lichtenstein GR, Bala M, Han C, et al. Infliximab improves quality of life in patients with Crohn's disease. Inflamm Bowel Dis 2002;8: 237-43.

65. Myint AM, Leonard BE, Steinbusch HW, Kim YK. Th1, Th2, and Th3 cytokine alterations in major depression. J Affect Disord 2005; 88:167-73.

66. Parissis JT, Adamopoulos S, Rigas A, et al. Comparison of circulating proinflammatory cytokines and soluble apoptosis mediators in patients with chronic heart failure with versus without symptoms of depression. Am J Cardiol 2004;94:1326-8.

67. Kubera M, Lin AH, Kenis G, et al. Anti-inflammatory effects of antidepressants through suppression of the interferon-gamma/ interleukin-10 production ratio. J Clin Psychopharmacol 2001;21: 199-206.

68. Lowry $\mathrm{CA}$, Hollis $\mathrm{JH}$, de Vries $\mathrm{A}$, et al. Identification of an immune-responsive mesolimbocortical serotonergic system: potential role in regulation of emotional behavior. Neuroscience 2007;146:756-72.

69. Rook GAW, Lowry CA. The hygiene hypothesis and psychiatric disorders. Trends Immunol 2008;29:150-8.

70. Aggarwal BB, Shishodia S, Sandur SK, et al. Inflammation and cancer: how hot is the link? Biochem Pharmacol 2006;72:1605-21.

71. Pikarsky E, Porat RM, Stein I, et al. NF-kappaB functions as a tumour promoter in inflammation-associated cancer. Nature 2004; 431:461-6.

72. Arnott CH, Scott KA, Moore RJ, et al. Expression of both TNFalpha receptor subtypes is essential for optimal skin tumour development. Oncogene 2004;23:1902-10.

73. Flossmann E, Rothwell PM. Effect of aspirin on long-term risk of colorectal cancer: consistent evidence from randomised and observational studies. Lancet 2007;369:1603-13.

74. Murphy SJ, Anderson LA, Johnston BT, et al. Have patients with esophagitis got an increased risk of adenocarcinoma? Results from a population-based study. World J Gastroenterol 2005;11:7290-5.

75. Wang HY, Wang RF. Regulatory T cells and cancer. Curr Opin Immunol 2007;19:217-23.

76. Deans C, Rose-Zerilli M, Wigmore S, et al. Host cytokine genotype is related to adverse prognosis and systemic inflammation in gastro-oesophageal cancer. Ann Surg Oncol 2007;14:329-39. 